\title{
Lessons from the epidemiology of neuropsychiatric disorders in older people
} Lições da epidemiologia dos transtornos neuropsiquiátricos em idosos Cássio Machado de Campos Bottino

Programa Terceira Idade (PROTER) do Instituto de Psiquiatria do Hospital das Clínicas da Faculdade de Medicina da Universidade de São Paulo (HC-FMUSP), São Paulo SP, Brazil.

\section{Correspondence}

Cássio Machado de Campos Bottino Rua Pedroso Alvarenga 755 / conj 21 04531-011 São Paulo SP - Brasil E-mail:cbottino@usp.br

\section{Conflict of interest}

There is no conflict of interest to declare.

Received 16 January 2012 Received in final form 19 January 2012 Accepted 26 January 2012

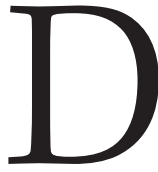
emographic changes that have occurred in Brazil have been widely publicized in recent years, showing the aging process of the Brazilian population. This is a worldwide phenomenon, which has occurred since the $20^{\text {th }}$ century, and it is unparalleled in human history, affecting countries globally, due to the persistent increase in absolute and relative number of older people, with profound impact on the economic and social spheres of human life. Aging is a long-lasting phenomenon, with the proportion of older people rising from $8 \%$, in 1950 , to $10 \%$, in 2000 , and an estimated $21 \%$, in $2050^{1}$.

The United Nations (UN) estimates for 2005, pointed to Brazil as belonging to the group of ten countries with the largest population of people aged 60 years or more, and estimates indicate that Brazil, in 2050, will be one of the six countries that have more than 10 million over 80 years-old. Among developing nations, Brazil has the highest percentage increase of the elderly population worldwide, with the group above 60 years-old increasing by about 23 times from 1950 to 2050, while its population as a whole is expected to grow about 4.5 times during this period ${ }^{1}$.

Therefore, we can imagine the impact that these demographic changes can have on our health care system. The neuropsychiatric disorders are among the most severe and disabling conditions affecting older people, and some articles published in recent years started to provide a bigger picture regarding the most prevalent diseases in this age range.

One of the first of these papers described that the prevalence of dementia in the population over 65 years-old, living in Catanduva, in the state of São Paulo, was $7.1 \%{ }^{2}$. The estimated prevalence of dementia found in another study carried out in São Paulo city, was $12.9 \%$ in the population over 60 years $^{3}$, figures equal to or higher than the prevalence rates of dementia found in developed countries ${ }^{4}$. Assessing the factors associated with dementia, the authors reported that age, especially above 70 years-old, lack of formal education, history of stroke, head trauma, diabetes, and epilepsy were associated with increased Odds Ratio of dementia and while the history of tumor/cancer, arthritis, current work and frequent reading of books were associated with reduced Odds Ratio of dementia in Brazilian studies ${ }^{4}$.

We can conclude from these data that the prevalence of dementia is similar or even higher in our country, and that Alzheimer's disease and vascular dementia are the most frequent causes of dementia. It is also well-known that dementia has a profound effect upon the patients' families and in this number of this journal, Camargos et al. ${ }^{5}$ showed the results of interviews performed in Brasilia, with 311 caregivers of people with or without dementia. The authors pointed out that the use of psychotropic drugs (benzodiazepines or antidepressants) was more frequent among caregivers of patients with dementia (11.4\%) compared to caregivers of patients without dementia (4.3\%). These results stress the need to increase resources to the medical care of older people with dementia and their families, suggesting that the control of chronic diseases and healthy lifestyles can possibly reduce the impact of such disease in future years.

Changing the topic to alcohol abuse and dependence, these conditions have different characteristics in the elderly than in young adults, with less consumption of alcohol, less severe dependence symptoms, less frequent legal and social problems, but more severe 
physical complications (malnutrition, falls, hypertension, gastrointestinal and cardiovascular disease, cancer, and drug interactions), increasing mortality, morbidity, and cost of care. Brazilian studies have shown prevalence from 9 to $12 \%$ of alcohol-related problems in elderly men, figures five to six times higher than women ${ }^{6,7}$. These results show that the prevalence of alcohol-related problems in Brazil is high and that factors associated with this condition are male gender, young-older, low educational level and socioeconomic status, smoking, and cognitive and/or functional impairment.

Regarding the prevalence of depression in the community, we can cite recent studies, as published by Blay et al. ${ }^{8}$, who described depressive morbidity rates of $22 \%$ (male $18 \%$; female $-25.2 \%$ ) in elderly people residing in cities of Rio Grande do Sul state, and the study by Costa et al. ${ }^{9}$, who found prevalence rates of depressive episode, $19.2 \%$ in elderly residents in the city of Bambuí, in Minas Gerais. The prevalence rates of these two studies are among the highest previously published studies with elderly people in the world.

These prevalence figures are compelling, indicating that, for dementia, alcohol-related problems and depression morbidity, the most common neuropsychiatric disorders affecting older people, our health system will face an enormous challenge, now and in the near future. The implementation of systematic screening for these conditions in primary care and the organization of resources in secondary and tertiary health units to correctly diagnose and treat these patients are essential to start dealing with these public health issues. Moreover, the knowledge about risk factors should be used to start initiatives, which can decrease the incidence of these problems in the future.

\section{References}

1. United Nations Department of Economic and Social Affairs (2002). World Population Ageing 1950-2050.

2. Herrera E Jr, Caramelli P, Silveira AS, Nitrini R. Epidemiologic survey of dementia in a community-dwelling Brazilian population. Alzheimer Dis Assoc Disord 2002;16:103-108.

3. Bottino CM, Azevedo D Jr, Tatsch M, et al. Estimate of dementia prevalence in a community sample from São Paulo, Brazil. Dementia Geriatric Cognitive Disord 2008;26:291-299.

4. Lopes MA, Hototian SR, Reis GC, Elkis H, Bottino CM. Systematic review of dementia prevalence 1994 to 2000. Dementia Neuropsychologia 2007;1:230-240.

5. Camargos EF, Souza AB, Nascimento AS, et al. Use of psychotropic medications by caregivers of elderly patients with dementia: is this a sign of caregiver burden? Arq Neuropsiquiatr 2012;70:169-174.
6. Hirata ES, Nakano EY, Junior JA, Litvoc J, Bottino CM. Prevalence and correlates of alcoholism in community-dwelling elderly living in São Paulo, Brazil. Int J Geriatr Psychiatry 2009;24:1045-1053.

7. Castro-Costa E, Ferri CP, Lima-Costa MF, et al. Alcohol consumption in late-life - the first Brazilian National Alcohol Survey (BNAS). Addict Behav 2008;33:1598-1601.

8. Blay SL, Andreoli SB, Fillenbaum GG, Gastal FL. Depression morbidity in later life: prevalence and correlates in a developing country. Am J Geriatr Psychiatry 2007;15:790-799.

9. Costa E, Barreto SM, Uchoa E, Firmo JO, Lima-Costa MF, Prince M. Prevalence of International Classification of Diseases, 10th Revision common mental disorders in the elderly in a Brazilian community: The Bambui Health Ageing Study. Am J Geriatr Psychiatry 2007; 15:17-27. 